\title{
Biomimetic Approach for Root Caries Prevention Using a Proanthocyanidin-Rich Agent
}

\author{
S. Pavan ${ }^{a}$ Q. Xie ${ }^{b}$ A.T. Hara ${ }^{c}$ A.K. Bedran-Russo ${ }^{a}$ \\ Departments of a Restorative Dentistry and bediatric Dentistry, University of Illinois at Chicago, College of \\ Dentistry, Chicago, III., and 'Department of Preventive and Community Dentistry, Oral Health Research Institute, \\ Indiana University School of Dentistry, Indianapolis, Ind., USA
}

\section{Key Words}

Grape seed extract • Proanthocyanidin • Remineralization • Root caries

\begin{abstract}
The aim of this study was to evaluate the effects of a proanthocyanidin-rich grape seed extract (GSE) on the in vitro demineralization of root dentine. Root fragments were obtained from sound human teeth. The fragments were randomly assigned to different treatments solutions: GSE, fluoride (F), GSE+F and distilled water (control). Samples were treated daily for $30 \mathrm{~min}$ and subjected to a $\mathrm{pH}$ cycling artificial caries protocol using demineralization cycles (2.2 $\mathrm{mm} \mathrm{CaCl} 2 \times \mathrm{H}_{2} \mathrm{O}, 2.2 \mathrm{mM} \mathrm{KH_{2 }} \mathrm{PO}_{4}, 50 \mathrm{~mm}$ acetic acid, $\mathrm{pH}$ 4.3) for $6 \mathrm{~h}$ and remineralization cycles (20 mM HEPES, 2.25 $\mathrm{mM} \mathrm{CaCl} 2 \times \mathrm{H}_{2} \mathrm{O}, 1.35 \mathrm{mM} \mathrm{KH}_{2} \mathrm{PO}_{4}, 130 \mathrm{mM} \mathrm{KCl}, \mathrm{pH}$ 7.0) for $17.5 \mathrm{~h}$. Mineral loss $(\Delta \mathrm{Z})$ and lesion depth (LD) were determined after 18 days of treatment/pH cycling, by transverse microradiography. GSE was able to minimize $\Delta Z$ and LD compared with the control group ( $p<0.0001)$. The GSE+F and $F$ groups showed the lowest values of $\Delta Z$ and LD ( $p<$ $0.05)$, with no statistically significant differences between them ( $p=0.554$ and $p=0.726$, respectively). A biomimetic approach to strengthen root dentine using GSE results in decreased rates of root demineralization and may be used in conjunction with $\mathrm{F}$ to prevent root caries.
\end{abstract}

Copyright $\odot 2011$ S. Karger AG, Basel

\section{KARGER}

Fax +41613061234 E-Mail karger@karger.ch www.karger.com
() 2011 S. Karger AG, Basel

Accessible online at: www.karger.com/cre
The success in prevention and disease control during the last century allowed the elderly population to maintain their permanent dentition into later life [Shay, 2004]. As a consequence, dental caries has become one of the most significant health problems facing older adults. More than half of the elderly who are dentate are affected by either coronal or root caries [Saunders and Meyerowitz, 2005], and a $23.3 \%$ incidence of root caries is estimated in this population [Griffin et al., 2004].

Dentine is a calcified tissue, which has an organic matrix (30 vol\%) containing fibrillar type I collagen (90\%) [Linde, 1989] and non-collagenous proteins such as phosphoproteins and proteoglycans (10\%) [Embery et al., 2001; Septier et al., 2001; Bedran-Russo et al., 2008]. Ultrastructural studies of root caries suggest that during the caries process, the mineral part of dentine is dissolved by acids produced by bacteria, exposing the organic matrix to breakdown by bacterially derived enzymes, as well as by host-derived enzymes such as matrix metalloproteinases present within the dentine and in the gingival crevicular fluid [Kawasaki and Featherstone, 1997; Nakornchai et al., 2004; Chaussain-Miller et al., 2006]. If preserved, the organic matrix of dentine can provide the major framework for mineralization and plays an important role in the process of remineralization of eroded and carious dentine [Ganss et al., 2004; Nakornchai et al., 2004; Hara et al., 2005].
Ana Karina Bedran-Russo

Department of Restorative Dentistry (MC 555), UIC College of Dentistry

801, South Paulina Street, Room 551

Chicago, IL 60612-7212 (USA)

Tel. +1 312413 9581, E-Mail bedran@uic.edu 
While fluoride $(\mathrm{F})$ is a well-established method to prevent and inhibit caries lesions [Ten Cate and Duijsters, 1983; Fure and Lingström, 2009], novel therapies focused on the prevention and reduction of root caries progression should be proposed by the application of substances that affect the organic dentine matrix content to promote remineralization as well as prevent organic matrix degradation. Recently, natural products with antibacterial and remineralization potential have been investigated on root dentine caries [Xie et al., 2008; Petti and Scully, 2009]. Using a biomimetic approach, selective natural agents stabilize and strengthen dentine by induction of exogenous collagen cross-linking, interaction with non-collagenous proteins and remineralization [Bedran-Russo et al., 2007, 2008, 2010; Xie et al., 2008]. The term dentin biomodifiers is suited for these agents due to their ability to interact with various extracellular matrix components to increase mechanical properties, decrease biodegradation rates and possibly promote mineral nucleation $[\mathrm{Be}-$ dran-Russo et al., 2007, 2008, 2010].

The grape seed extract (GSE) investigated herein is a flavonoid obtained from the seeds of Vitis vinifera. Its active constituents are proanthocyanidins (PA) and represent a variety of flavan-3-ol, catechin [Aron and Kennedy, 2008], which is a scavenging free radical required for absorption of calcium [Ishikawa et al., 2005]. In addition, PA increase collagen synthesis, accelerate the conversion of soluble collagen into insoluble collagen during development [Cetta et al., 1977; Rao et al., 1983] and decrease the rate of enzymatic degradation of collagen matrices [Han et al., 2003; Chaussain-Miller et al., 2006; Walter et al., 2008; Macedo et al., 2009]. Due to the lack of definitive preventive approaches for root caries, the exploitation of the tissue structure itself can provide important insights into novel therapies for dentine root caries. The objective of this study was to evaluate the effects of dentine biomodification using a PA-rich GSE on the in vitro demineralization of root dentine using microradiography analysis. The null hypothesis tested was that GSE would not prevent the demineralization of human root dentine.

\section{Materials and Methods}

\section{Experimental Design}

This study was conducted following a completely randomized design with treatment as the only experimental factor, at 4 levels: control - deionized water; GSE - 6.5\% GSE solution; F - 1,000 ppm F solution as NaF; GSE+F - 1,000 ppm NaF solution plus $6.5 \%$ GSE. The experimental unit was root dentin fragment, with
10 repetitions per group $(\mathrm{n}=10)$. The outcome measures were mineral loss $(\Delta \mathrm{Z}$; vol\% mineral $\times \mu \mathrm{m})$ and lesion depth (LD; $\mu \mathrm{m})$, obtained by transversal microradiography.

\section{Specimen Preparation}

Twelve extracted sound human third molars were used in this study. They were thawed, cleaned, kept frozen $\left(-20^{\circ} \mathrm{C}\right)$ for $2-3$ weeks and used following the Institutional Review Board Committee of the University of Illinois at Chicago (protocol no. 20060229). The roots were cut from the crowns at the cementoenamel junction with a low-speed diamond blade (Isomet 1000, Buehler, Lake Bluff, Ill., USA). Four-millimeter-thick slices were obtained from the cervical third of the roots and 3-4 fragments $(4 \times 5 \mathrm{~mm})$ were obtained per slice using a cylindrical diamond bur (No. 557D, Brasseler, Savannah, Ga., USA) in a high-speed handpiece. The root surfaces were polished under running water with 1,000grit silicon carbide paper to remove cementum. A total of 40 fragments were obtained and sealed with acid-resistant nail polish (Revlon Corp., New York, N.Y., USA) except for a $3 \times 4 \mathrm{~mm}$ window.

\section{Treatments and $p H$ Cycling}

The root fragments were randomly assigned to four different groups $(\mathrm{n}=10)$ according to the treatment: control - deionized water; GSE - 6.5\% GSE solution (MegaNatural Polyphenolics, Madera, Calif., USA), $\mathrm{pH}=7.4 ; \mathrm{F}-1,000 \mathrm{ppm}$ F solution as $\mathrm{NaF}$ (Fisher Chemical, Fair Lawn, N.J., USA); GSE+F - 1,000 ppm $\mathrm{NaF}$ solution plus $6.5 \% \mathrm{GSE}, \mathrm{pH}=7.4$. The amount of free $\mathrm{F}$ in each solution was assessed by an ion-selective electrode (96-09) connected to an ion analyzer (EA-940; Orion, Boston, Mass., USA), which was previously calibrated with a series of eight standard solutions (from 0.03 to $10.0 \mu \mathrm{g} / \mathrm{ml} \mathrm{F}$ ) in triplicate. The groups were individually immersed into $50 \mathrm{ml}$ of the respective solutions for $30 \mathrm{~min}$, under constant agitation at $37^{\circ} \mathrm{C}$. The specimens were then subjected to a demineralization $\mathrm{pH}$ cycling model. Each group was individually immersed in $150 \mathrm{ml}$ of demineralization solution $\left(2.2 \mathrm{mM} \mathrm{CaCl}_{2} \times \mathrm{H}_{2} \mathrm{O}, 2.2 \mathrm{mM} \mathrm{KH}_{2} \mathrm{PO}_{4}\right.$, $50 \mathrm{~mm}$ acetic acid, $\mathrm{pH} 4.3$ ) for $6 \mathrm{~h}$, washed with distilled water, dried with absorbent paper and immersed in $150 \mathrm{ml}$ of remineralization solution (20 mM HEPES, $2.25 \mathrm{mM} \mathrm{CaCl}_{2} \times \mathrm{H}_{2} \mathrm{O}, 1.35$ $\mathrm{mM} \mathrm{KH}_{2} \mathrm{PO}_{4}, 130 \mathrm{mM} \mathrm{KCl}, \mathrm{pH}$ 7.0) for $17.5 \mathrm{~h}$. During the $\mathrm{pH}$ cycling, the specimens were kept at $37^{\circ} \mathrm{C}$ under constant shaking. The treatment/pH cycling regimen lasted 18 days and all the solutions were made fresh and changed daily. After 18 days, the roots fragments were rinsed with distilled water, dried and sectioned longitudinally through the lesions with a low-speed water-cooled diamond blade (Isomet 1000, Buehler) to obtain $300-\mu \mathrm{m}$-thick slices that were further polished to approximately $180 \pm 20 \mu \mathrm{m}$ thickness using 600-and 1,000-grit silicone carbide paper.

\section{Transverse Microradiography}

The sections were X-rayed together with an aluminium stepwedge at $20 \mathrm{kV}$ and $30 \mathrm{~mA}$ for $65 \mathrm{~min}$. Microradiographic plates (High Resolution UF Plate, Microchrome Technology, Inc., San Jose, Calif., USA) were processed (all chemicals from Eastman Kodak Co., Rochester, N.Y., USA) and the radiographic images were taken from the microscope (EOM, Carl Zeiss Inc., Jena, Germany) to the computer with a camera (KP-120U, Hitachi Denshi Ltd., Tokyo, Japan). The images were analyzed with dedicated 
computer software (TMR, transverse microradiography version 1.26, Inspektor Research Systems BV, Amsterdam, The Netherlands). $\Delta \mathrm{Z}$ was obtained by computing the area obtained by plotting the vol\% mineral profile towards LD in each dentine section, with the sound dentine set as $48 \mathrm{vol} \%$ mineral [van der Veen et al., 1996]. LD was defined as the distance from the surface to the site the mineral content of which was more than $95 \%$ of the sound dentine.

\section{Statistical Analysis}

Means and standard deviations were calculated for $\Delta \mathrm{Z}$ (vol\% mineral $\mathrm{x} \mu \mathrm{m})$ and $\mathrm{LD}(\mu \mathrm{m})$. The data were statistically analyzed using one-way ANOVA (effect of treatments) and post-hoc Fisher's PLSD tests $(\alpha=0.05)$. The statistical analysis was performed using Statview 5.01 software (SAS, Cary, N.C., USA).

\section{Results}

The values of free $F$ ions of each treatment solution and the values of $\Delta \mathrm{Z}$ and LD are summarized in table 1. GSE treatment was able to minimize $\Delta \mathrm{Z}$ and LD when compared to the control group $(\mathrm{p}<0.0001)$. The GSE+F and F groups showed the lowest $\Delta \mathrm{Z}$ and LD values when compared to the control and GSE groups ( $\mathrm{p}<0.05)$. No statistically significant differences were observed between $\mathrm{F}$ and GSE+F ( $p=0.554)$. Representative transverse microradiographs of each group are presented in figure 1. A hypermineralization process, characterized as a radiopaque band, was observed on several samples exposed to $\mathrm{F}$ therapy (fig. 1b).

\section{Discussion}

The present study evaluated a PA-rich extract associated or not with $\mathrm{F}$ to prevent the demineralization of root dentine using an artificial caries model. It is known that the root caries process involves two different steps: (1) dissolution of hydroxyapatite by acidic challenge and (2) degradation of the organic dentine matrix by proteases from dentine, saliva or bacteria [Kawasaki and Featherstone, 1997; Nakornchai et al., 2004; ChaussainMiller et al., 2006]. It is well known that the structure and stability of collagen matrix is critical for proper mineralization [Ganss et al., 2004; Hara et al., 2005]. Hence, in the absence of collagenous matrix, $\mathrm{H}^{+}$ions can penetrate the porous dentine, causing severe $\Delta \mathrm{Z}$ even in the presence of high amounts of $\mathrm{F}$ [Ganss et al., 2004].

While F compounds are the current method to decrease the development or progression of caries due to its
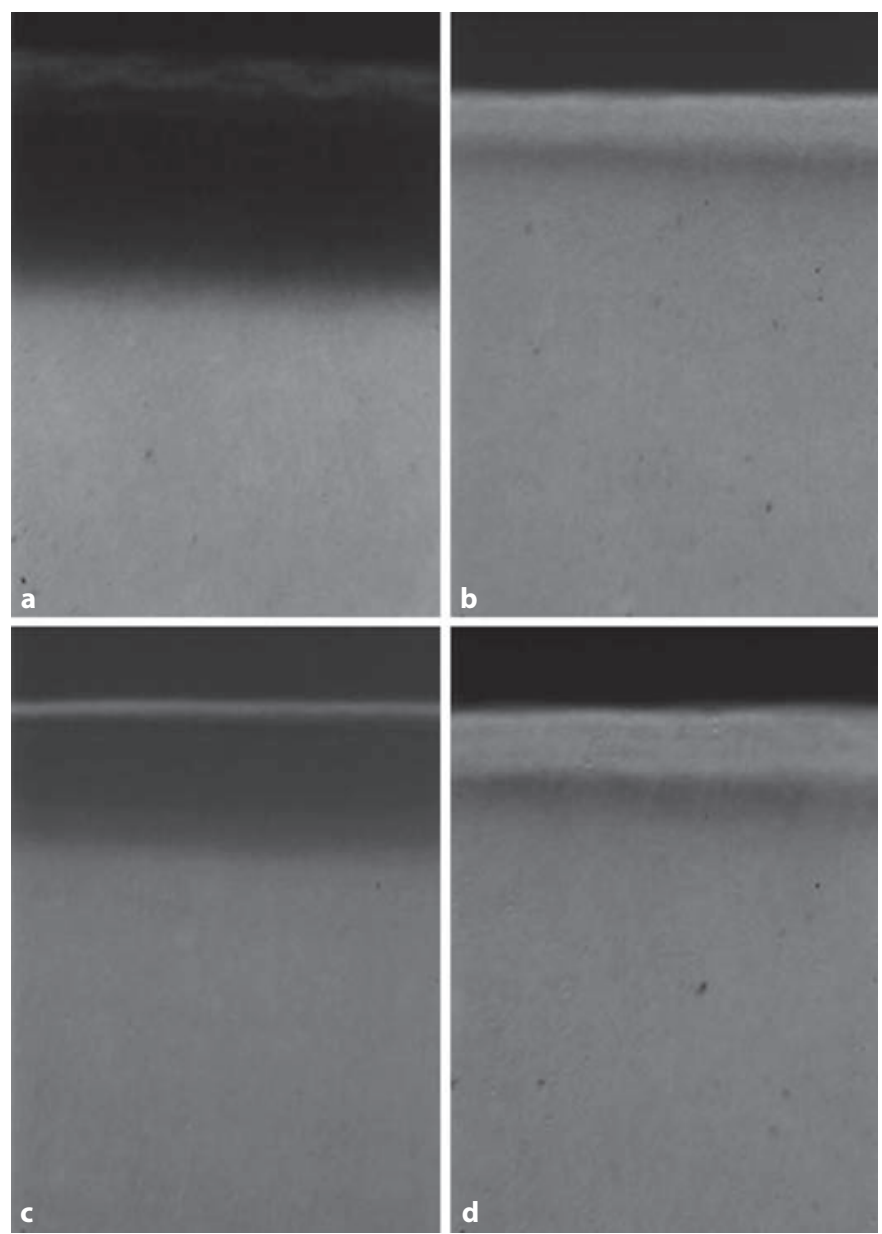

Fig. 1. Representative microradiograph images of in vitro caries lesions on root surfaces following 18 days of $\mathrm{pH}$ cycling model. a The control group showed the deepest and least mineralized lesion. b F treatment reduced demineralization of root dentine. A hypermineralization process could be observed in 7 samples. c GSE-treated dentine showed formation of a well-defined outer mineralized layer and reduced LD. d Small LD and greater mineral deposition can be see on the root surface of a GSE+F fragment.

Table 1. Microradiography results of $\Delta \mathrm{Z}$ and LD of artificial carious lesions subjected to different surface treatments

\begin{tabular}{lccr}
\hline Group & $\begin{array}{l}\text { Mineral loss } \\
(\Delta \mathrm{Z})\end{array}$ & $\begin{array}{l}\text { Lesion depth } \\
(\mathrm{LD})\end{array}$ & \multicolumn{1}{l}{$\begin{array}{l}\text { Fluoride } \\
(\mathrm{ppm})\end{array}$} \\
\hline Control & $4,300 \pm 1,306^{\mathrm{a}}$ & $174 \pm 30^{\mathrm{a}}$ & $0.01 \pm 0.00$ \\
Fluoride & $495 \pm 231^{\mathrm{c}}$ & $85 \pm 20^{\mathrm{c}}$ & $1,002.72 \pm 2.23$ \\
GSE & $2,570 \pm 794^{\mathrm{b}}$ & $109 \pm 20^{\mathrm{b}}$ & $0.04 \pm 0.00$ \\
GSE+fluoride & $706 \pm 343^{\mathrm{c}}$ & $81 \pm 18^{\mathrm{c}}$ & $849.42 \pm 1.89$
\end{tabular}

Values are means $\pm \mathrm{SD}$. Fluoride (ppm) is the free fluoride concentration of the treatment solutions used. Different letters indicate statistical differences among groups $(\mathrm{p}<0.05)$. 
capacity to promote tooth remineralization and reduce the rate of demineralization [Ten Cate and Duijsters, 1983; Fure and Lingström, 2009], the presence of a rich organic content in root dentine highlights the need for alternative approaches to manage caries in this substrate. In the present study, $\mathrm{F}$ was used as a positive control, being effective in reducing lesion progression in root dentine, as demonstrated by lower $\Delta \mathrm{Z}$ and shallower lesions. Furthermore, a hypermineralization process, characterized as a radiopaque band, was observed on several samples (fig. 1b). This band has a greater amount of mineral than sound dentine, increased hardness [Xie et al., 2008] and may improve the root's resistance against acid challenge [Hong et al., 2003].

GSE alone also reduced the progression of the lesion on root dentine, but at a relatively lower scale compared to the F control group. Therefore, the null hypothesis that GSE would not prevent the demineralization of dentine root was rejected. Dentine carious lesions present a non-remineralized outer layer with decreased crosslinking among collagen molecules and a large amount of denatured collagen [Kuboki et al., 1977; Nakornchai et al., 2004], while the inner remineralizable portion presents decreased collagen cross-links without protein denatured [Kuboki et al., 1977; Nakornchai et al., 2004]. Using $\mathrm{pH}$ cycling for modeling caries progression, we speculated that GSE maintains the integrity of the dentine organic matrix similar to that of the inner carious layer, thus promoting increased remineralization and decreased demineralization. The formation of hydrogen bonding between amine, carboxyl and the phenolic hydroxyl groups may be the primary mechanism for PA and collagen interactions [Han et al., 2003]. GSE effectively improves the mechanical properties [Bedran-Russo et al., 2007, 2008] and decreases the degradation rates of sound and caries-affected dentine [Macedo et al., 2009], indicating the ability of this natural agent to interact with and modify the dentine collagen. GSE may also play a role in decreasing collagen digestibility by its inhibitory effect on proteases such as intrinsic metalloproteinases [Koide and Daito, 1997]. In addition, the preservation of the collagen network may produce a mechanical barrier to acid diffusion and mineral release and also facilitate mineral precipitation during the remineralization process.

The GSE-treated group (fig. 1c) depicted the formation of a well-defined outer mineralized layer when compared to the control group (fig. 1a). This layer may be the result of insoluble complex deposition formed by GSE when mixed with remineralizing solution [Xie et al.,
2008]. The present study highlights for the first time the direct substrate effect of PA on the demineralization of root dentine surfaces. Other studies have reported its effect using a bacterial model [Walter et al., 2008], and therefore the antibacterial effect of GSE cannot be discarded. Remineralization protocols have also observed a significant positive effect of GSE [Xie et al., 2008]. Further studies need to be developed to identify the active constituents of GSE and maximize its effect on the substrate.

The combined use of GSE and F could not promote a greater mineral deposition on root surface when compared to the application of $\mathrm{F}$ alone. This may be due to the interaction between GSE and F since the smaller amount of free $\mathrm{F}$ was present on the GSE+F solution when compared with the F solution (table 1). In this study it was hypothesized that the GSE molecules would bind to collagen, possibly combining with $\mathrm{Ca}^{2+}$ present in the remineralizing solution to allow a greater mineralization process, as previously suggested for remineralization of artificial root caries [Xie et al., 2008]. This was based on previous studies where GSE had enhanced the bone mass in rats by facilitating mineral deposition [Kamitani et al., 2004; Ishikawa et al., 2005; Yahara et al., 2005]. However, the addition of $F$ to the GSE solution may have affected the dynamic of the remineralization process. It is possible that the GSE effect was minimized by the precipitation of minerals on the surface of the lesion, catalyzed by the $\mathrm{F}$ action. While this prevented further demineralization during cycling, explaining the better results of group GSE+F compared to GSE (fig. 1d vs. c), it also could have prevented remineralization of deeper parts of the lesion, not allowing a hypothetical synergistic effect of F and GSE to be observed. Therefore, no clear differences were seen when comparing GSE+F and F (fig. 1d vs. b). Possibly, lower concentrations of $\mathrm{F}$ can reduce mineral precipitation on the surface of the lesion, contributing to a better overall remineralization response. However this deserves further testing.

Based on the results obtained in this in vitro study, it can be concluded that biomodification of the tooth substrate using GSE results in decreased rates of root dentine demineralization. A biomimetic alternative for root caries prevention may be used to strengthen the organic matrix and increase remineralization, associated or not to $\mathrm{F}$. 


\section{Acknowledgement}

This study was supported by a research grant from the USA National Institutes of Health (NIH-NIDCR No. DE017740).

\section{Disclosure Statement}

The authors would like to state that the Board of Trustees of the University of Illinois holds a provisional patent on the use of collagen cross-linking agents for dental restorative treatment and preventive dentistry in which Dr. Ana Bedran-Russo is the inventor.

\section{References}

Aron PM, Kennedy JA: Flavan-3-ols: nature, occurrence and biological activity. Mol Nutr Food Res 2008;52:79-104.

Bedran-Russo AK, Pereira PN, Duarte WR, Drummond JL, Yamauchi M: Application of crosslinkers to dentine collagen enhances the ultimate tensile strength. J Biomed Mater Res B Appl Biomater 2007;80:268-272.

Bedran-Russo AK, Pashley DH, Agee K, Drummond JL, Miescke KJ: Changes in stiffness of demineralized dentine following application of collagen crosslinkers. J Biomed Mater Res B Appl Biomater 2008;86B: 330-334.

Bedran-Russo AK, Castellan CS, Shinohara MS, Hassan L, Antunes A: Characterization of biomodified dentin matrices for potential preventive and reparative therapies. Acta Biomater 2011;7:1735-1741.

Cetta G, Pallavicini G, Tenni R, Bisi C: Influence of flavonoid-copper complexes on cross linking in elastin. Ital J Biochem 1977;26: 317-327.

Chaussain-Miller C, Fioretti F, Goldberg M, Menashi S: The role of matrix metalloproteinases (MMPs) in human caries. J Dent Res 2006;85:22-32.

-Embery G, Hall R, Waddington R, Septier D, Goldberg M: Proteoglycans in dentinogenesis. Crit Rev Oral Biol Med 2001;12:331-349.

-Fure S, Lingström P: Evaluation of different fluoride treatments of initial root carious lesions in vivo. Oral Health Prev Dent 2009; 7: 147-154.

Ganss C, Klimek J, Starck C: Quantitative analysis of the impact of the organic matrix on the fluoride effect in erosion progression in human dentine using longitudinal microradiography. Arch Oral Biol 2004;49:931-935.
Griffin SO, Griffin PM, Swann JL, Zlobin N: Estimating rates of new root caries in older adults. J Dent Res 2004;83:634-638.

Han B, Jaurequi J, Tang BW, Nimni ME: Proanthocyanidin: a natural crosslinking reagent for stabilizing collagen matrices. J Biomed Mater Res 2003;65A:118-124.

- Hara AT, Ando M, Cury JA, Serra MC, Gonzalez-Cabezas C, Zero DT: Influence of the organic matrix on root dentine erosion by citric acid. Caries Res 2005;39:134-138.

Hong L, Ettinger RL, Watkins CA, Wefel JS: In vitro evaluation of fluoride varnish on overdenture abutments. J Prosthet Dent 2003;89: 28-36.

Ishikawa M, Maki K, Tofani I, Kimura K, Kimura M: Grape seed proanthocyanidins extract promotes bone formation in rat's mandibular condyle. Eur J Oral Sci 2005;113:47-52.

Kamitani Y, Maki K, Tofani I, Nishikawa Y, Tsukamoto K, Kimura M: Effects of grape seed proanthocyanidins extract on mandibles in developing rats. Oral Dis 2004;10:27-31.

Kawasaki K, Featherstone JDB: Effects of collagenase on root demineralization. J Dent Res 1997;76:588-595.

Koide T, Daito M: Effects of various collagen crosslinking techniques on mechanical properties of collagen film. Dent Mater J 1997;16:1-9.

Kuboki Y, Ohgushi K, Fusayama T: Collagen biochemistry of the two layers of carious dentine. J Dent Res 1977;56:1233-1237.

Linde A: Dentine matrix proteins: composition and possible functions in calcification. Anat Rec 1989;224:154-166.

Macedo GV, Yamauchi M, Bedran-Russo AK: Effects of chemical cross-linkers on cariesaffected dentine bonding. J Dent Res 2009; 88:1096-1100.

Nakornchai S, Atsawasuwan P, Kitamura E, Surarit R, Yamauchi M: Partial biochemical characterisation of collagen in carious dentine of human primary teeth. Arch Oral Biol 2004;49:267-273.
Petti S, Scully C: Polyphenols, oral health and disease: a review. J Dent 2009;37:413-423.

Rao CN, Rao VH, Steinmann B: Bioflavonoidmediated stabilization of collagen in adjuvant-induced arthritis. Scand J Rheumatol 1983;12:39-42.

Saunders RH Jr, Meyerowitz C: Dental caries in older adults. Dent Clin North Am 2005;49: 293-308.

Septier D, Hall RC, Embery G, Goldberg M: Immunoelectron microscopic visualization of pro- and secreted forms of decorin and biglycan in the predentine and during dentine formation in the rat incisor. Calcif Tissue Int 2001;69:38-45.

Shay K: The evolving impact of aging America on dental practice. J Contemp Dent Pract 2004; 15:101-110.

Ten Cate JM, Duijsters PP: Influence of fluoride in solution on tooth demineralization I. Chemical data. Caries Res 1983;17:193-199.

van der Veen MH, Tsuda H, Arends J, ten Bosch JJ: Evaluation of sodium fluorescein for quantitative diagnosis of root caries. J Dent Res 1996;75:588-593.

-Walter R, Miguez PA, Arnold RR, Pereira PNR, Duarte WR, Yamauchi M: Effects of natural cross-linkers on the stability of dentine collagen and the inhibition of root caries in vitro. Caries Res 2008;42:263-268.

Xie Q, Bedran-Russo AK, Wu CD: In vitro remineralization effects of grape seed extract on artificial root caries. J Dent 2008;36:900906.

Yahara N, Tofani I, Maki K, Kojima K, Kojima Y, Kimura M: Mechanical assessment of effects of grape seed proanthocyanidins extract on tibial bone diaphysis in rats. J Musculoskelet Neuronal Interact 2005;5:162-169. 